\title{
PENGARUH RASIO RECYCLE TERHADAP PRODUKSI BIOGAS MENGGUNAKAN REAKTOR TANGKI BERPENGADUK BERBANTUKAN MEMBRAN ULTRAFILTRASI PADA KONDISI TRANSISI $\left(45^{\circ} \mathrm{C}\right)$
}

\author{
THE EFFECT OF RECYCLE RATIO ON BIOGAS PRODUCTION USING CONTINUOUS \\ STIRRED TANK REACTOR WITH ULTRAFILTRATION MEMBRANE ASSISTANCE AT \\ TRANSITION CONDITION $\left(45^{\circ} \mathrm{C}\right)$
}

\author{
Bambang Trisakti" , Irvan, M.Taufan Anantama, Arbie Saldi Zusri, Alfian Haikel Lubis, Sri Eka Cahyani \\ Departemen Teknik Kimia, Fakultas Teknik, Universitas Sumatera Utara \\ Jalan Almamater Kampus USU Medan, 20155, Indonesia \\ *Email : b_trisakti@yahoo.com
}

\begin{abstract}
Abstrak
Digestasi anaerobik merupakan salah satu solusi permasalahan lingkungan dan sumber energi untuk kebutuhan energi saat ini. Dalam digestasi anaerobik, material organik didegradasi oleh bakteri, yang dilangsungkan tanpa oksigen, dan mengkonversinya menjadi campuran metana dan karbon dioksida. POME dapat terdegradasi secara anaerobik dalam digester anaerob untuk menghasilkan biogas. Penelitian ini bertujuan untuk meningkatkan konversi dari biogas yang dihasilkan dengan menggunakan digester jenis Continous Stirred Tank Reactor (CSTR) dengan volume 2 liter dalam proses metanogenesis dengan mendaur ulang kembali effluent yang dihasilkan melewati membran ultrafiltrasi pada kondisi transisi $\left(45^{\circ} \mathrm{C}\right)$. Proses dilakukan dengan memvariasikan rasio recycle yaitu $0 \%, 15 \%$ dan $25 \%$ pada HRT 6 hari dengan kondisi pH $7 \pm 0,2$. Produksi biogas rata - rata tertinggi dicapai pada rasio recycle $25 \%$ yaitu $33,15 \times 10^{-5} \mathrm{~L} / \mathrm{mg}$ VS.hari, dengan komposisi metana, karbon dioksida, dan hidrogen sulfida masing-masing sebesar $79 \%$; $19 \%$; dan 0,006 \%, dengan degradasi VS dan COD masing-masing sebesar 39,58 \% dan 66,33\%. Untuk komposisi kandungan $\mathrm{CH}_{4}$ tertinggi diperoleh pada variasi rasio recycle $15 \%$ yaitu sebesar $85 \%$ sedangkan untuk komposisi karbondioksida, dan hidrogen sulfida masing-masing sebesar $14 \%$; dan $0,0076 \%$.
\end{abstract}

Kata kunci: metanogenesis, continous stirred tank reactor, digestasi anaerobik, rasio recycle

\begin{abstract}
Anaerobic digestion is one of solution to environmental problems and energy sources for current energy needs. In anaerobic digestion, organic material is degraded by bacteria, which is carried out without oxygen, and converts it to a mixture of methane and carbon dioxide. POME can be degraded anaerobically in anaerobic digester to produce biogas. This study aims to increase the conversion of biogas produced using a 2 liter Continuous Stirred Tank Reactor (CSTR) type digester in the methanogenesis process by recycling the effluent produced through the ultrafiltration membrane in a transition condition $\left(45^{\circ} \mathrm{C}\right)$. The process is carried out by varying the recycle ratio, which is $0 \%, 15 \%$ and $25 \%$ on HRT 6 days with a condition of $\mathrm{pH} 7 \pm 0.2$. The highest average biogas production was achieved at the $25 \%$ recycle ratio of $33.15 \times 10-5 \mathrm{~L} / \mathrm{mg}$ VS. day, with the composition of methane, carbon dioxide and hydrogen sulfide each of $79 \% ; 19 \%$; and $0.006 \%$, with degradation of VS and COD of $39.58 \%$ and $66.33 \%$ respectively. For the composition of the highest $\mathrm{CH}_{4}$ content obtained at a variation of the $15 \%$ recycle ratio which is equal to $85 \%$ while for the composition of carbon dioxide, and hydrogen sulfide each is $14 \%$; and $0.0076 \%$.
\end{abstract}

Keywords: metanogenesis, continuous stirred tank reactor, anaerobic digestion, recycle ratio

\section{Pendahuluan}

Negara Indonesia merupakan salah satu negara produsen dan pengekspor minyak kelapa sawit terbesar di dunia dibandingkan negara Malaysia [1]. Kelapa sawit adalah sumber makanan dan bahan bakar dengan hasil yang besar dan juga sangat efisien. Perkebunan kelapa sawit efektif untuk memproduksi bahan bakar alternatif pengganti bahan bakar fosil dan menangkap karbon dari atmosfer. Indonesia merupakan salah satu produsen minyak sawit terbesar di dunia, dan industri ini merupakan sektor ekspor pertanian yang paling tinggi nilainya selama dasawarsa terakhir [2]. Pada tahun 2017, Indonesia memiliki perkebunan kelapa sawit dengan luas areal sekitar 12,3 juta hektar dan dapat memproduksi berkisar 35,4 juta ton/tahun minyak kelapa sawit dan minyak inti sawit sebesar 7 juta ton/tahun [3]. 
Data peningkatan produksi minyak kelapa sawit disajikan pada tabel 1.

Tabel 1. Peningkatan Produksi Minyak Kelapa Sawit Indonesia [3]

\begin{tabular}{|c|c|c|c|}
\hline Tahun & $\begin{array}{c}\text { Luas } \\
\text { Areal } \\
\text { (juta } \\
\text { hektar) }\end{array}$ & $\begin{array}{c}\text { Produksi } \\
\text { Minyak } \\
\text { Kelapa } \\
\text { Sawit (juta } \\
\text { ton) }\end{array}$ & $\begin{array}{c}\text { Jumlah } \\
\text { Limbah } \\
\text { Cair } \\
\text { (juta ton) }\end{array}$ \\
\hline 2013 & 9,9 & 30,5 & 76,25 \\
\hline 2014 & 10,3 & 33 & 82,5 \\
\hline 2015 & 10,6 & 33 & 82,5 \\
\hline 2016 & 11,9 & 40 & 103,70 \\
\hline 2017 & 12,3 & 42,4 & 110 \\
\hline
\end{tabular}

Dengan meningkatnya jumlah ekspor minyak kelapa sawit Indonesia, maka timbul permasalahan lain mengenai minyak kelapa sawit, yaitu permasalahan limbah PKS [4].

Dengan penekanan produksi berkelanjutan, pengolahan limbah diharapkan meghasilkan energi dalam industri kelapa sawit. Pengolahan limbah cair pabrik kelapa sawit sudah dilakukan dengan anaerobik ponding system, filtrasi anaerobik, anaerobik fluidized bed reactor, upflow anaerobic sludge blanket (UASB), expanded granular sludge bed reactor (EGSB), anaerobic baffled reactor (ABR), anaerobic sequencing batch reactor (ASBR), continuous stirred tank reactor (CSTR), dan upflow anaerobic sludge fixed film (UASFF) [5].

Dalam proses pembuatan biogas dengan mengunakan digester anaerobik ini ditambahkan proses daur ulang pada lumpur sisa dari pembutan biogas dengan menggunakan membran (Ultrafiltration Membrane) yang bertujuan untuk meningkatkan konversi dari biogas yang dihasilkan [6]. Teknik pemisahan membran telah terbukti efektif. Metode untuk memisahkan padatan biomassa dari suspensi digester dan daur ulang tersebut menuju digester. Beberapa penelitian menggunakan membran pada proses anaerobik untuk mengolah berbagai perairan limbah menemukan bahwa Membrane Anarobic System (MAS) proses dipertahankan dan karena lama waktu retensi padatan mencair dan semua materi partikulat terurai. Membrane Anarobic System (MAS) ditemukan untuk menjadi sistem pengolahan biologi yang sukses yang dicapai efisiensi penyisihan Chemical Oxygen Demand (COD) yang tinggi dalam waktu singkat. Membrane Anarobic System (MAS) mampu beroperasi pada Solid Retention Time (SRT) tinggi dan cukup toleran terhadap variasi dalam influen beban Chemical Oxygen Demand (COD). Oleh karena itu, Membrane
Anarobic System (MAS) adalah alternatif yang baik untuk mengolah kadar air limbah tinggi, dan meningkatkan produksi metana untuk energi akan menjadi hasil tambahan yang berharga dari proses [6]

Dari penelitian yang dilakukan oleh Lubis (2018), dengan menggunakan proses digester anaerob HRT 6 hari pada suhu $45^{\circ} \mathrm{C}$ dengan laju pengadukan $250 \mathrm{rpm}$, diperoleh hasil terbaik produksi biogas yaitu sebesar $31,188 \times 10^{-5}$ L/mgVS.hari dengan variasi rasio recyecle $25 \%$. Produksi biogas pada variasi tanpa recycle dan pada variasi rasio recycle $15 \%$ yaitu 11,586 L/mgVS.hari dan 18,019 L/mgVS.hari [7], dan dari penelitian yang dilakukan oleh Cahyani (2018), dengan menggunakan proses digester anaerob HRT 6 hari pada suhu $30^{\circ} \mathrm{C}$ dengan laju pengadukan $250 \mathrm{rpm}$, diperoleh hasil terbaik produksi biogas yaitu sebesar $39,0335 \times 10^{-5}$ $\mathrm{L} / \mathrm{mgVS}$. hari dengan variasi rasio recyecle $25 \%$. Produksi biogas pada variasi tanpa recycle dan pada variasi rasio recycle $15 \%$ yaitu 19,308 L/mgVS.hari dan 28,715 L/mgVS.hari [8].

Oleh sebab itu penelitian ini penting dilakukan untuk memperbaiki secara teknis dalam pengolahan limbah cair kelapa sawit (LCPKS) menggunakan reaktor tangki berpengaduk dengan berbantukan membran ultrafiltrasi pada kondisi transisi $\left(45^{\circ} \mathrm{C}\right)$ dengan variasi rasio recycle yang telah ditentukan. Diharapkan dari penelitian ini dapat meningkatkan hasil produksi biogas dan mencapai kestabilan sistem dari yang pernah dicapai.

\section{Teori}

Digesti anaerob adalah multistage (hidrolisis, acidogenesis, acetogenesis dan metanogenesis) degradasi bahan organik dan berubah menjadi $\mathrm{CH}_{4}$ dan $\mathrm{CO}_{2}$ oleh aksi sekelompok mikroorganisme. Wong juga mengungkapkan bahwa, POME segar pertama kali diubah menjadi asam lemak mudah menguap (VFA) oleh bakteri pembentuk asam kemudian berubah menjadi $\mathrm{CH}_{4}$ dan $\mathrm{CO}_{2}$ dalam proses pencernaan anaerobik. Proses ini menghasilkan biogas seperti biometana dan biohidrogen melalui degradasi cepat senyawa organik dari POME [9].

Dalam digesti anaerob suhu merupakan faktor sangat penting yang mempengaruhi aktifitas mikroorganisme. Suhu optimal proses digester anaerob adalah $30-40{ }^{\circ} \mathrm{C}$. Suhu optimal untuk proses digestasi anaerobik terbagi menjadi 3 kondisi yaitu psikrofilik $<20{ }^{\circ} \mathrm{C}$, mesophilic $\left(30-40^{\circ} \mathrm{C}\right)$, dan thermophilic $\left(50-60^{\circ} \mathrm{C}\right)$ [10].

Faktor kunci berhasilnya mengendalikan stabilitas dan efesiensi proses adalah konfigurasi reaktor, Hydraulic Retention Time (HRT), 
Organic Loading Rate (OLR), pH, suhu, konsentrasi inhibitor, konsentrasi Total Volatile Fatty Acid (TVFA) dan komposisi substrat [11]. Selain itu, pada proses digesti anaerob juga sangat dipengaruhi oleh pengadukan. Pengadukan meningkatkan pendistribusian bakteri, substrat dan nutrisi kesuluruh reaktor serta untuk meyamakan keseragaman suhu dalam reaktor [11]. Selain itu, mikroba membentuk sistem stabilisasi yang unik dan berguna, yang aktif secara biologis dan mengurangi endapan. Berbagai jenis sistem pencernaan anaerobik ada di dunia. Proses pencernaan POME yang paling direkomendasikan termasuk filter anaerobik dan anaerobik fluidized bedreactors, up-flow anaerobic sludge blanket reactors (UASB), diperluas selimut lumpur granular (EGSB), reaktor anaerobik baffled (ABR), reaktor batch sekuens anaerobik (ASBR), kontinu reaktor tangki berpengaduk (CSTR) dan reaktor aliran lumpur anaerobik aliran naik (UASFF) [9].

Reaktor tangki berpengaduk kontinyu secara luas digunakan sebagai sarana untuk mengkonversi reaktan menjadi produk berharga dalam industri kimia. Fermentasi limbah organik menjadi biogas terbarukan terjadi dalam tiga fase yaitu cairan, padat dan fase gas. Mengendalikan kondisi optimum seperti yield gas, pengurangan substrat, $\mathrm{pH}$. Selain itu, perubahan laju pemuatan organik (OLR) dapat menyebabkan gangguan signifikan kinerja stabilitas CSTR [12].

Seiring perkembangan zaman penggunaan CSTR sudah semakin berinovasi salah satunya penggunaan membran sebagai pembantu mempertahankan waktu tinggal biomassa di dalam CSTR dan pemakaian kembali biomassa (recycle biomassa). Menurut Ferguson manfaat daur ulang limbah dalam mengurangi penambahan basa yang diperlukan. sebagai hasil daur ulang dapat meminimalkan total biaya operasional perawatan karena sebagian besar penghematan dalam penambahan garam bikarbonat [13]. Dalam proses pembuatan biogas dengan mengunakan digester anaerobik ini ditambahkan proses daur ulang pada lumpur sisa dari pembutan biogas dengan menggunakan membran (Ultrafiltration Membrane) yang bertujuan untuk meningkatkan konversi dari biogas yang dihasilkan [6]. Penelitian yang dilakukan oleh Abdurrahman et.al., (2011) adalah pemanfaatan membran sebagai recycle dari effluent reaktor berpengaduk berbahan baku LCPKS dalam pembuatan biogas. Hasil penelitian menunjukkan semakin banyaknya umpan hasil recycle akan meningkatkan nilai pertumbuhan mikroba, penguraian VS, penguraian COD, dan jumlah produksi biogas, namun untuk komposisi gas metana yang diperoleh paling baik pada umpan recycle pada rasio pertama, seiring peningkatan umpan recycle maka komposisi gas metana akan menurun [6].

\section{Metodologi Penelitian \\ Bahan Baku Penelitian}

Bahan-bahan yang digunakan adalah Natrium Bikarbonat $\left(\mathrm{NaHCO}_{3}\right)$, Asam Klorida ( $\mathrm{HCl})$, Kalium Dikromat $\left(\mathrm{K}_{2} \mathrm{Cr}_{2} \mathrm{O}_{7}\right)$, Raksa (II) Sulfat $\left(\mathrm{HgSO}_{4}\right)$, Perak Sulfat $\left(\mathrm{Ag}_{2} \mathrm{SO}_{4}\right)$, Asam Sulfat $\left(\mathrm{H}_{2} \mathrm{SO}_{4}\right)$, Ferro Ammonium Sulfat (FAS), dan ferroin. Bahan baku utama yang digunakan berupa limbah cair pabrik kelapa sawit yang diambil dari fat pit Rambutan PTPN III. Hasil analisis karakteristik LCPKS disajikan pada Tabel 2, Adapun metode uji yang digunakan yaitu APHA (American Public Health Association).

Tabel 2. Hasil Analisis Karakteristik LCPKS dari PTPN III Rambutan [7]

\begin{tabular}{|c|c|c|c|}
\hline \multirow{2}{*}{$\begin{array}{c}\text { Para } \\
\text { meter }\end{array}$} & Satuan & Hasil Uji & Metode Uji \\
\hline $\mathrm{pH}$ & - & $3,90-4,50$ & APHA 4500-H \\
\cline { 2 - 4 } $\mathrm{COD}$ & $\mathrm{mg} / \mathrm{L}$ & 40.288 & APHA 5220B \\
\hline $\mathrm{TS}$ & $\mathrm{mg} / \mathrm{L}$ & $14.000-28.000$ & APHA 2540B \\
\hline $\mathrm{VS}$ & $\mathrm{mg} / \mathrm{L}$ & $10.000-26.000$ & APHA 2540E \\
\hline $\mathrm{TSS}$ & $\mathrm{mg} / \mathrm{L}$ & $21.040-25.160$ & APHA 2540D \\
\hline $\mathrm{VSS}$ & $\mathrm{mg} / \mathrm{L}$ & $9.040-17.160$ & APHA 2540E \\
\hline $\mathrm{SCO}$ & $\mathrm{mg} / \mathrm{L}$ & 19.424 & APHA 5220B \\
\hline
\end{tabular}

\section{Prosedur Penelitian}

Rangkaian peralatan yang digunakan dalam proses metanogenesis adalah seperti yang terlihat pada Gambar 1. Pada tahap hidrolitik dilakukan penbibitan benih mikroba berupa starter yang berasal dari pilot plant yang dicampurkan dengan subtrat limbah cair kelapa sawit (LCPKS) yang berasal dari Pabrik Kelapa sawit PTPN III Rambutan dengan perbandingan starter : LCPKS, $20 \%: 80 \%$ dari volume fermentor. Fermentor dioperasikan pada temperatur $45^{\circ} \mathrm{C}$, kecepatan pengaduk $250 \mathrm{rpm}, \mathrm{pH} 7( \pm 0,2)$, dan di targetkan beropreasi pada HRT 6. Untuk meningkatkan suhu dari kondisi ambient ke suhu $45{ }^{\circ} \mathrm{C}$ dilakukan dengan cara bertahap yaitu meningkatkan $2{ }^{\circ} \mathrm{C} /$ hari yang dibagi menjadi dua waktu yaitu $1{ }^{\circ} \mathrm{C}$ pada pagi hari, dan $1{ }^{\circ} \mathrm{C}$ pada malam hari. Pengontrolan $\mathrm{pH}$ dilakukan agar $\mathrm{pH}$ tetap konstan dengan penambahan natrium bikarbonat $\left(\mathrm{NaHCO}_{3}\right)$. Dilakukan juga beberapa langkah untuk mencapai HRT target, yaitu dengan menurunkan HRT secara bertahap dimulai dari HRT 25, 15, 10 dan sampai ke HRT 6. Proses ini dinamakan proses loading up. Pertumbuhan mikroba dalam fermentor pada 
proses loading up dapat ditunjukan dengan hasil pengukuran dan penentuan $\mathrm{pH}$, alkalinitas, TS, VS, TSS, VSS, COD serta volume biogas.

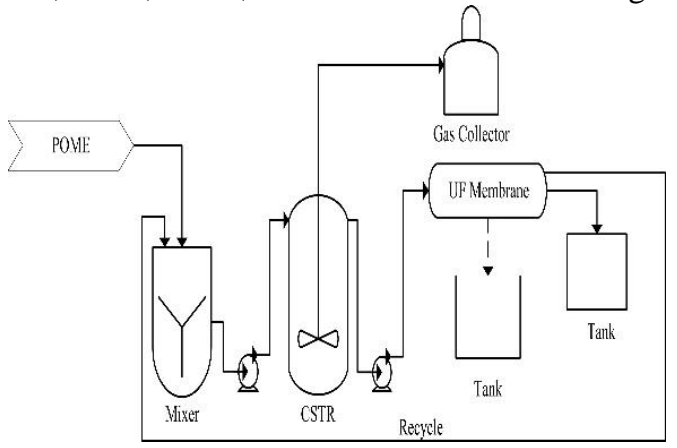

Gambar 1. Diagram Alir Proses Pembuatan Biogas Berbantukan UF Membran

Membran yang digunakan pada penelitian ini adalah jenis membran aliran cross flow seperti pada Gambar 2 dimana pada jenis aliran ini terdapat dua aliran keluar yaitu permeat, dan retentat. Pada penelitian ini memanfaatkan hasil permeat berupa effluent yang tidak lolos melewati membran, sedangkan retentat dapat dibuang sebagai effluent dengan nilai COD yang rendah. Selama penelitian ini dilaksanakan, tentu perlu dilakukannya treatment pembersihan membran agar kinerja membran tetap stabil. Treatment ini dilakukan dengan pencucian menggunakan aquadest yang dialirkan dari retentat agar sisa kotoran yang tertinggal pada membran dapat dibersihkan selama 10 menit hingga aquadest yang keluar tetap jernih atau tidak ada kotoran yang tersisa, metode ini biasa dikenal dengan istilah back -wash.

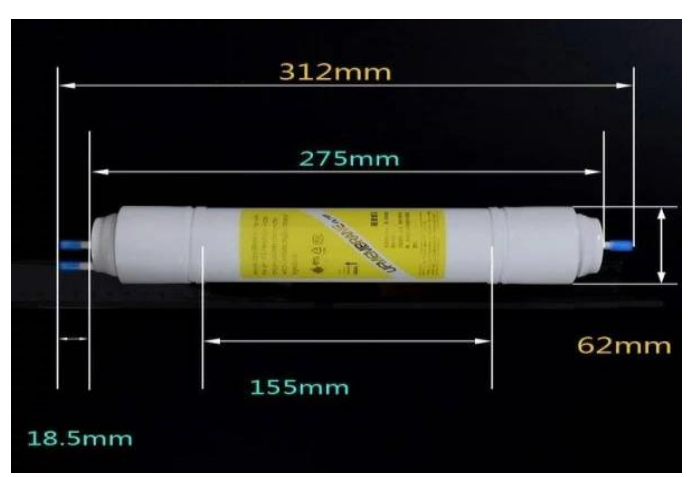

Gambar 2. Membran Ultrafiltrasi

\section{Hasil}

Pengaruh Rasio Recycle Terhadap Alkalinitas

Pada proses metanogenesis, alkalinitas dapat menunjukkan kestabilan suatu proses yang ada di dalam suatu fermentor seperti penguraian senyawa organik oleh mikroba. Gambar 3 menunjukkan pengaruh rasio recycle terhadap alkalinitas. Gambar 3 menunjukkan nilai alkalinitas pada perubahan rasio recycle dari tanpa recycle, dan $15 \%$ mengalami fluktuasi terhadap peningkatan rasio recycle. Hasil alkalinitas pada tanpa recycle berada pada nilai $2.900-3.700 \mathrm{mg} / \mathrm{L}$, rasio recycle $15 \%$ berada pada nilai $2.900-3.400 \mathrm{mg} / \mathrm{L}$ dan pada rasio recycle $25 \%$ berada pada nilai $2.900-3.200$ $\mathrm{mg} / \mathrm{L}$.

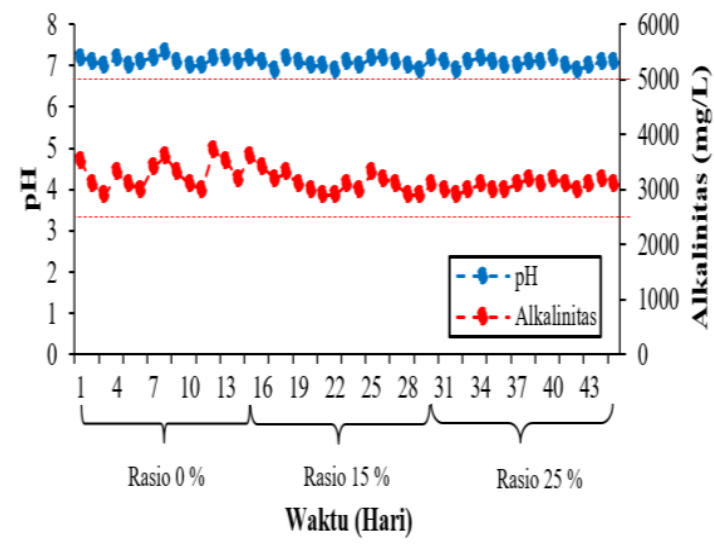

Gambar 3. Pengaruh Rasio Recycle Terhadap Alkalinitas

Dari gambar 3, dapat dilihat bahwa pengaruh rasio recycle terhapadap alkalinitas sangat kuat, ini dibuktikan dengan hasil penelitian tanpa rasio recycle yang kondisi alkalinitasnya tidak stabil dibandingkan dengan hasil yang menggunakan rasio recycle yaitu pada rasio recycle $15 \%$, dan 25\%. Menurut Abdurahman et.al (2011) rasio recycle sangat membantu untuk menjaga alkalinitas didalam fermentor atau dengan penambahan garam kapur atau bikarbonat [6]. Oleh karena itu, pada variasi rasio recycle tahapan metanogenesis VFA dengan temperatur $45^{\circ} \mathrm{C}$, tidak memberikan perubahan yang signifikan terhadap alkalinitas seiring dengan peningkatan rasio recycle. Grafik alkalinitas mengalami fluktuasi pada kisaran nilai alkalinitas yang masih dalam rentang batas wajar yaitu $2500 \mathrm{mg} / \mathrm{L}-5000 \mathrm{mg} / \mathrm{L}$ [14].

Produksi rata-rata total biogas mengalami peningkatan. Volume biogas tertinggi yang diperoleh pada rasio recycle $25 \%$ yaitu dengan nilai $33,15 \times 10^{-5} \mathrm{~L} / \mathrm{mg}$ VS.hari. Produksi biogas pada tanpa recycle yaitu $14,331 \times 10^{-5} \mathrm{~L} / \mathrm{mg}$ VS.hari dan pada rasio recycle $15 \%$ yaitu 20,606 x $10^{-5} \mathrm{~L} / \mathrm{mg}$ VS.hari mengalami peningkatan. Menurut penelitian yang dilakukan oleh Abdurrahman et.al., (2011) produksi biogas menggunakan membran mengalami peningkatan seiring dengan peningkatan umpan recycle dari membran, dimana nilai produksi biogas 
meningkat dari 280,5 L/hari menjadi $540 \mathrm{~L} /$ hari [6].

\section{Kesimpulan}

Rasio recycle sangat berpengaruh terhadap kestabilan sistem dalam proses fermentasi anaerobik dengan penetapan $\mathrm{pH}$ dan alklinitas masing-masing pada rentang 6,9-7,6 dan 2.900 $3.900 \mathrm{mg} / \mathrm{l}$, yang masih dalam rentang wajar. Penggunaan membrane UF dapat mempengaruhi kestabilah fermentor dikarenakan mampu menjaga kestabilan alkalinitas dalam proses pembentukan biogas. Produksi biogas rata - rata tertinggi dicapai pada rasio recycle $25 \%$ yaitu $33,15 \times 10^{-5} \mathrm{~L} / \mathrm{mg}$ VS.hari, dengan komposisi metana, karbon dioksida, dan hidrogen sulfida masing-masing sebesar $79 \%$; $19 \%$; dan 0,006 \%, dengan degradasi VS dan COD masing-masing sebesar $39,58 \%$ dan $66,33 \%$. Untuk komposisi kandungan $\mathrm{CH}_{4}$ tertinggi diperoleh pada variasi rasio recycle $15 \%$ yaitu sebesar $85 \%$ sedangkan untuk komposisi karbondioksida, dan hidrogen sulfida masing-masing sebesar $14 \%$; dan $0,0076 \%$

\section{Daftar Pustaka}

[1] B. Trisakti, V. Manalu, Irvan, Taslim, M. Turmuzi, Acidogenesis of Palm Oil Mill Effluent to Produce Biogas: Effect of Hydraulic Retention Time and $\mathrm{pH}$, World Conference on Technology, Innovation and Entrepreneurship, 195, 2466-2474, 2015.

[2] World Growth, The Economic Benefit of Palm Oil to Indonesia. www.worldgrowth.org, Diakses pada 08 Juli 2016, 2011.

[3] Hendaryati, D. Dewi dan Y. Arianto, Statistik Perkebunan Indonesia Tree Crop Estate Statistics of Indonesia, Published by Sekretariat Direktorat Jenderal Perkebunan: Jakarta, 2016.

[4] A. Yan, Makalah Seminar Umum Pemanfaatan Limbah Kelapa Sawit (Elaeis Guineensis Jaqs), Program Studi Agronomi, Jurusan Budidaya Pertanian, Fakultas Pertanian, Universitas Gadjah Mada: Yogyakarta, 2014.

[5] Mishra, Puranjan, Thakur, L. Singh, Z. Wahid, and M. Sakinah, Enhanced hydrogen production from palm oil mill effluent using two stage sequential dark and photo fermentation, International Journal of Hydrogen Energy, Volume 41, 2016.

[6] Abdurahman, Y. Rosli, dan N. Azhari, Development of a membrane anaerobic system (MAS) for palm oil mill effluent
(POME) treatment. Desalination 266 208-21, 2011.

[7] A. H. Lubis, Pengaruh Rasio Recycle Terhadap Produksi Biogas Menggunakan Reaktor Tangki Berpengaduk Dengan Bantuan Membran Ultrafiltrasi Pada Temperatur $45^{\circ} \mathrm{C}$, Skripsi, Departemen Teknik Kimia. Fakultas Teknik, Universitas Sumatera Utara : Medan, 2018.

[8] S. E. Cahyani, Pengaruh Rasio Recycle Terhadap Produksi Biogas Menggunakan Reaktor Tangki Berpengaduk Dengan Bantuan Membran Ultrafiltrasi Pada Temperatur $30{ }^{\circ} \mathrm{C}$, Skripsi, Departemen Teknik Kimia, Fakultas Teknik, Universitas Sumatera Utara, Medan, 2018.

[9] Zhang, X. Ojing, J. Yan, H. Li, S. Chekani, L. Liu, Investigation of thermal integration between biogas production and upgrading, Energy Conversion and Management vol. 102 page 131-139, 2015.

[10] Sasongko, Wedo, Produksi Biogas Dari Biomassa Kotoran Sapi Dalam Biodigester Fix Dome Dengan Pengenceran dan Penambahan Agitasi, Thesis, Program Pasca Sarjana, Universitas Sebelas Maret Surakarta, 2010.

[11] F. Aulia, B. Trisakti, Mahdalena, dan Irvan, Metanogenesis Limbah Cair Pabrik Kelapa Sawit (LCPKS) pada Temperatur $55^{\circ} \mathrm{C}$ : Pengaruh Variasi Pengadukan Terhadap Produksi Biogas Menggunakan Reaktor Batch, Skripsi, Jurnal Teknik Kimia Universitas Sumatera Utara, 2014.

[12] Cahyari, Sarto, S. Syamsiah dan A Prasetya, Performance of continuous stirred tank reactor (CSTR) on fermentative biohydrogen production from melon waste, IOP Conference Series: Materials Science and Engineering, Jilid 162, Halaman 12013, 2013.

[13] Q. Y. Han, Z. Hu, T. Q. Hong, dan G. Wei $\mathrm{Gu}$, Performance of An Anaerobic Treating Soybean Processing Wastewater With and Without Effluent Recyecle, Asian Journal of Chemistry, Volume 28, No 3, 2002.

[14] Choong, Y. Yaw, K. W. Chou, dan I. Norli, Strategies for improving biogas production of palm oil mill effluent (POME) anaerobic digestion, Renewble and Sustainable Energy Reviews, Volume 82, Part 3, 2017. 